CERN PPE/94-63.

29.03.1994

\title{
AGEING STUDIES WITH MICRO-STRIP GAS CHAMBERS
}

\author{
R. Bouclier, C. Garabatos, G. Manzin, G. Million, F. Sauli, T. Temmel and L. Shekhtman \\ CERN, Geneva, Switzerland
}

\begin{abstract}
Micro-strip gas chambers (MSGCs) are intrinsically capable of operating at very high radiation fluxes, up to and above $10^{6}$ particles $\mathrm{mm}^{-2} \mathrm{~s}^{-1}$. It was noticed, however rather early in the development of the detectors that sustained exposure to radiation could produce irreversible damage (decrease of gain and discharges) easily assimilated with the ageing phenomena which are known to occur in proportional counters, and caused by the polymerization of gas molecules in the avalanche process.

We describe the results of a systematic investigation of ageing under sustained irradiation of MSGC plates manufactured on several substrates and operated in clean laboratory containers as well as in mechanical assemblies better suited for the use of the detectors in experimental set-ups. In the best experimental conditions, we have demonstrated survival without degradation of the detectors up to a collected charge of $120 \mathrm{mC} \mathrm{cm}^{-1}$; in less than optimal conditions, ageing is observed already at a level of a few $\mu \mathrm{C} \mathrm{cm}-1$. A careful selection of the operating gas and of the materials used in manufacturing appears mandatory to guarantee survival of the devices in a high radiation environment such as that of the Large Hadron Collider (LHC) detectors.

The present study has been realized at CERN in the framework of the RD-28 Collaboration (Development of micro-strip gas chambers for high-rate applications).
\end{abstract}

Submitted to Nuclear Instruments and Methods in Physics Research 


\section{INTRODUCTION}

Micro-strip gas chambers (MSGCs) were introduced by Oed [1]. Having the active elements, anode and cathode strips, etched on insulating supports using a highaccuracy photo-lithographic technology, MSGCs allow the realization of gaseous detectors with distances between anodes an order of magnitude shorter than in conventional multi-wire proportional chambers (MWPCs). The reduction of pitch brings considerable advantages in terms of rate capability, localization accuracy and multiparticle resolution [2-5], making MSGCs a very attractive proposition for experimental set-ups at high luminosity colliders. A great effort is at present being undertaken to fully understand the operating characteristics of the new device and to find cheap and reliable manufacturing processes; a recent account of major achievements can be found in the status report of the RD-28 Collaboration at CERN [6].

It appeared rather early in the development of MSGCs that, in order to operate efficiently at high radiation fluxes, the use of supports having insulating properties that are too god (such as boro-silicate glass or ceramics) should be avoided. Indeed, a fraction of the charge produced by the gaseous amplification process appears to stick to the surface of the insulator between strips, adversely modifying the electric field with a consequent fast, rate-dependent gain drop [7, 8]. This "charging up" effect can be overcome either by surface conditioning the plates with ion implantation [2] or deposition of a thin-film semi-conducting layer [9-11] which reduces the surface resistivity to $10^{14}-10^{15} \Omega / \mathrm{o}$, or by the use of supports having a low bulk resistivity such as electronconducting glasses in the range $10^{9}$ to $10^{12} \Omega \mathrm{cm}$ [12]. It has been experimentally demonstrated that MSGCs made on resistive supports can withstand, without gain modification, radiation rates up to and above $10^{6} \mathrm{~mm}^{-2} \mathrm{~s}^{-1}$ at an avalanche size of around $10^{5}$ electrons $[5,11]$.

However, reaching high rates in the detectors has made manifest another raterelated effect: ageing $[8,13]$. This is an old problem encountered in gaseous devices, and has been extensively studied with MWPCs (see, for example, ref. [14]). Permanent damage to the electrodes after extended irradiation, with a severe degradation of performance, has been associated with the production in the avalanches of polymeric compounds that stick to anodes and cathodes and perturb the counting action or induce discharges. Possibly because of the smaller effective area used for charge multiplication on the anode strips (a few microns as compared to about a hundred microns for wires ), or to a more effective polymerization process, MSGCs have been found to be particularly prone to fast ageing. The present study addresses both the question of long-term stability of the performance of the detectors under sustained irradiation in laboratory conditions, and of the restrictions in the choice of the operating gas and of the materials used to manufacture the chambers.

\section{EXPERIMENTAL PROCEDURES AND SET-UPS}

\subsection{Long-term irradiation}

The experimental set-up used for high-rate long-term controlled irradiation studies has been described previously [5]. The detector under test is mounted on a precision $\mathrm{x}-\mathrm{y}$ displacement table in front of a collimated $\mathrm{X}$-ray beam, provided by a generator (Fig. 1); the beam intensity can be adjusted by varying the current in the tube and/or changing the size and geometry of the collimator. Although not mono-energetic, 
the X-ray tubes we use provide a well-defined peak at an energy corresponding to the fluorescence of the anode material ( 6 and $8 \mathrm{keV}$ for iron and copper respectively). The small contribution of the continuous energy spectrum due to bremsstrahlung can be neglected for most purposes. For the majority of the measurements effective collimated beam areas of 3 to $10 \mathrm{~mm}^{2}$ were used, in order to ensure obliteration of the chambers' micro-structure; the irradiated spot could be reproducibly shifted by using the displacement table. The X-ray beam from the generator, strongly attenuated, was used to irradiate a single-wire proportional counter, in series on the gas line, in order to allow monitoring both of beam intensity and of gain variations due to ambient and gas composition changes in long-term exposures. At present, we are operating two identical high-rate irradiation stations, capable of providing photon rates above $10^{6} \mathrm{~mm}^{-2} \mathrm{~s}^{-1}$. At an avalanche size of $3 \times 10^{5}$ and $200 \mu \mathrm{m}$ pitch, this corresponds to charge rates per unit length of strip of about $0.1 \mu \mathrm{C} \mathrm{cm}^{-1} \mathrm{~s}^{-1}\left(\approx 10 \mathrm{mC} \mathrm{cm}^{-1}\right.$ per day of operation).

For some of the measurements, namely in cases when we expected fast ageing, or for short-term controls, chambers have been irradiated in additional test stations using the $5.9 \mathrm{keV} \mathrm{X}$-rays from an ${ }^{55} \mathrm{Fe}$ source; in this case, gain monitoring as described was not required.

The MSGC plates used for lifetime measurements were of identical design and small size, with an active area of about $10 \mathrm{~cm}^{2}$. Groups of cathodes (20 to 50 strips) were connected together to the recording electronics; all anodes were ganged and connected to the HV power supply through a high value $(1 \mathrm{M} \Omega)$ protection resistor; for measurements at the highest values of the current, this value had to be decreased to a few hundred $\mathrm{k} \Omega$ to limit voltage drops. At low and moderate irradiation rates, pulse height spectra could be directly measured, whilst at the higher flux we recorded the current measuring the voltage drop on a $100 \mathrm{k} \Omega$ load resistor, grounding the cathodes, or directly with a picoamperemeter. The absolute gain $M$ was estimated by measuring successively, in identical conditions, the current $I$ and the counting rate $R$ per unit surface with the expression $I=R S q_{o} M$, where $S$ is the irradiated surface and $q_{o}$ the charge released in the gas by each $\mathrm{X}$-ray conversion $(\approx 220$ electrons for $6 \mathrm{keV})$. The accuracy of the gain value measured with this procedure is estimated to be about $5 \%$. Simpler procedures using the recorded pulse height and the electronics sensitivity are not accurate enough, since the pulse height in a MSGC for a fixed gain depends on the detector's capacitance, the number of strips connected together, the presence and connections of the back plane [15].

\subsection{Gas mixers and tubing}

In the early studies of long-term irradiation we used a standard CERN gas mixer; however, it was realized quite soon that outgassing from various organic components used in the system (joints, plastic tubes etc.) could seriously affect the lifetime of the detector [5]. Therefore, we have built for the ageing studies a "clean" gas mixing set-up, shown in Fig. 2, with the components summarized in Table 1. The system was designed and assembled taking precautions to eliminate all possible polluting agents, and exclusively using stainless-steel pipes in the rack and down to and away from detectors. All parts were chemically cleaned before assembly with a standard procedure: washing in an alkaline solution*, rinsing with distilled water and ethyl alcohol, followed by baking in vacuum for several hours at $100{ }^{\circ} \mathrm{C}$.

\footnotetext{
* FLUKA RBS5O
} 
Table 1: Characteristics of the clean gas mixer

\begin{tabular}{|l|l|l|}
\hline \multicolumn{1}{|c|}{ Component } & \multicolumn{1}{c|}{ Materials } & \multicolumn{1}{c|}{ Type or comments } \\
\hline $\begin{array}{l}\text { Mass flowmeter: } \\
\text { Ar }\end{array}$ & $\begin{array}{l}\text { Stainless steel } \\
\text { VITON Joint }\end{array}$ & $\begin{array}{l}\text { Bronkhorst High-Tech } \\
\text { 201C FA }\end{array}$ \\
\hline $\begin{array}{l}\text { Mass Flow meter: } \\
\text { DME }\end{array}$ & $\begin{array}{l}\text { Stainless steel } \\
\text { KALREZ Joint }\end{array}$ & $\begin{array}{l}\text { Bronkhorst High-Tech } \\
\text { 201C FA }\end{array}$ \\
\hline O2 Filter, Ar & $\begin{array}{l}\text { Chromium Trioxide } \\
\text { VITON Joint }\end{array}$ & $\begin{array}{l}\text { OXISORB } \\
\text { Messer Griesheim }\end{array}$ \\
\hline Filters & $2 \mu \mathrm{m}$ Stainless steel & SAGANA M6SFT2SS \\
\hline Tubing & Stainless steel & 4x6 and 2x3 mm \\
\hline $\begin{array}{l}\text { Connections, valves, } \\
\text { no-returns }\end{array}$ & $\begin{array}{l}\text { Stainless steel, PTFE Joints } \\
\text { TEFLON tape } \\
\text { VARIAN TORR-SEAL }\end{array}$ & Used for sealing leaks \\
\hline
\end{tabular}

To prevent air and other contaminants (such as oil vapours) from back-diffusing into the detectors, a $10 \mathrm{~m}$ long copper tube was mounted on the exhaust line, eliminating oil bubblers altogether.

All measurements were realized with an Ar-dimethylether (DME) 90-10 mixture. We used CERN stockroom standard research grade $\mathrm{Ar}^{*}$ and commercial $\mathrm{DME}^{+}$. An active filter in the argon line guarantees removal of oxygen and (to some extent) of water in the clean gas rack; micro-pore filters in both lines remove particulates and complex molecules.

It should be noted that the gas nature and purity is a dominant factor in determining the ageing properties in gas detectors. Whilst all precautions were taken in our experimental set-up to avoid unknown or uncontrolled sources of pollution, a rigorous study would require an on-line verification of the nature and amount of trace pollutant. This is routinely done in another research project at CERN, RD-10 [16], where a combined gas chromatograph-mass spectrometer and electron capture device are used for this purpose. The results of this research, particularly concerning gas purity and outgassing of materials relevant for MSGC construction and operation are being published separately $[17,18]$. In particular, these studies have suggested the use of DME-based mixtures rather than hydrocarbons in order to prevent fast ageing of the detectors (see also ref. [11]).

\subsection{Detector construction}

For the ageing measurements we have used several types of MSGC plates, similar in size and design but built on different substrates. All have a pitch (distance anode to cathode centres) of $100 \mu \mathrm{m}$; anodes and cathodes are $10 \mu \mathrm{m}$ and $80 \mu \mathrm{m}$ wide, respectively. The major characteristics of the plates are indicated in Table 2; the table indicates also the maximum X-ray flux at which plates can be operated before suffering from gain losses due to charging up (at an avalanche size of $2 \times 10^{5}$ ). Long-term, high-rate

\footnotetext{
* Purity 0.99996; nominal impurities 10 ppm $\mathrm{H}_{2} \mathrm{O}, 5$ ppm O 2.

+ Purity 0.9999; nominal impurities $50 \mathrm{ppmCO}_{2}+\mathrm{C}_{3}+\mathrm{CH}_{\mathrm{N}}$ : 1 ppm methanol; 50 ppm $\mathrm{H}_{2} \mathrm{O}$. Produced by Gerling-Holz, Hamburg, Germany.
} 
measurements could only be performed with detectors manufactured on electronconducting (e.c.) substrates.

Table 2: Materials of MSGC plates used for the irradiation

\begin{tabular}{|l|l|l|l|}
\hline Model & \multicolumn{1}{|c|}{ Source/Substrate } & \multicolumn{1}{c|}{ Strip metal } & \multicolumn{1}{c|}{ Max. rate } \\
\hline MS-1 & $\begin{array}{l}\text { SSPC NIIES } \\
\text { e.c. glass } \rho=10^{9} \Omega \mathrm{cm}\end{array}$ & Gold & $10^{7} \mathrm{~mm}^{-2} \mathrm{~s}^{-1}$ \\
\hline MS-2 & $\begin{array}{l}\text { SCHOTT S- } 8900 \\
\text { e.c. glass } \rho=10^{12} \Omega \mathrm{cm}\end{array}$ & Chromium & $10^{5} \mathrm{~mm}^{-2} \mathrm{~s}^{-1}$ \\
\hline MS-3 & $\begin{array}{l}\text { DESAG D263 } \\
\text { Ionic glass } \rho=10^{15} \Omega \mathrm{cm}\end{array}$ & Chromium & $10^{3} \mathrm{~mm}^{-2} \mathrm{~s}^{-1}$ \\
\hline
\end{tabular}

We have tested the radiation tolerance of MSGC plates assembled with different schemes and materials. As we will see, the best results have been consistently achieved by mounting the MSGC glass plates in a "clean box" with the minimum use of organic materials. Other, more practical construction schemes for the detectors have been tried, often with less than optimal and in some cases with quite bad results. Table 3 gives a summary list of the materials (with the exception of the MSGC plates themselves) used for three representative assemblies.

Table 3: Materials used for three MSGC assembles

\begin{tabular}{|l|l|l|}
\hline \multicolumn{1}{|c|}{ Detector } & \multicolumn{1}{|c|}{ Component } & \multicolumn{1}{c|}{ Materials } \\
\hline & Container & Stainless steel \\
& Window & Aluminium \\
& Joint & Indium \\
& MSGC Passivation & EPOTEK E505 \\
& MSGC Electrical contacts & EPOTEK E204 \\
& Gas inlets & Stainless steel \\
\hline \multirow{5}{*}{ Fibreglass box } & Frames & STESALITE W4411 \\
& O-rings & Neoprene \\
& Window & Mylar-Aclar \\
& Epoxy & Araldite CIBA 106 \\
& Gas inlets & Nylon \\
\hline \multirow{3}{*}{ Glass box } & Frame & Boro-silicate glass \\
& Epoxy & EPOTEK E505 \\
& MSGC passivation & EPOTEK E505 \\
& Gas inlets & Stainless steel + 10 cm PTFE \\
\hline
\end{tabular}

The clean box (Fig. 3) consists of a cylindrical stainless steel container with gas and signal feed-through, where MSGC plates can easily be mounted on ceramic insulating rods. A thin aluminium window on one side allows the detector to be exposed to the X-ray beam; two cover plates are sealed to the main body with indium O-rings. No organic materials are used in the box, which has been thoroughly cleaned using the procedure described above for the gas system. Voltages are provided and signals extracted using vacuum-grade metal-ceramic feed-through.

The fibreglass box (Fig. 4) is a conventional stack of printed circuits and frames assembled with synthetic rubber O-rings, with a mechanical mounting scheme developed 
in analogy with conventional MWPC detectors. A mylar-aclar foil as window on the front side allows the exposure of the detector to radiation; gas inlets and outlets are connected to the gas mixer with stainless steel tubes.

Fig. 5 shows the most promising assembly scheme, named the "glass box". A thin ( $0.5 \mathrm{~mm}$ thick) glass frame, $3 \mathrm{~mm} \mathrm{high}^{+}$, is pasted directly on the MSGC plate using an ultra-low vapour pressure epoxy; similarly, the drift electrode is glued on the top of the structure making the chamber leak-proof. For the prototype chambers used in the ageing tests we have used as drift electrode a $300 \mu \mathrm{m}$ thick D263 glass foil made conductive on the inner side by an evaporated thin layer of indium-tin oxide, which has the advantage of being transparent thus allowing inspection of the strips. The gas feed-through are realized on the glass frame itself as shown in the figure. The MSGC plate extends beyond the frame by a few mm on two opposite sides to allow electrical connection to the anode and cathode strips.

\section{EXPERIMENTAL RESULTS}

\subsection{General comments}

Ageing processes in gaseous detectors are well known to be affected by the presence of minute amounts of pollutants in the system, at a level hard to detect unless sophisticated analytical systems are used. For the measurements described here an actual monitoring of pollution levels was not made, and the self-consistency of data, in case of doubt, was verified by repeating exposures in conditions known to allow a low or negligible rate of ageing (the clean-clean set-up, see later). This is particularly important for long-term measurements, lasting several weeks, and necessitating replacement of the gas bottles and other interventions on detectors and tubing prone to introduce pollution.

The amount of polymerization causing ageing is known to be a function of the amount of charge released in the gas and collected by the electrodes, and depends only weakly on the dose rate and gain [15]. It is conventional to characterize ageing of gaseous detectors by plotting the normalized gas gain measured as a function of collected charge per unit length of wire (or strip for MSGCs). All our measurements were realized at gas gains of about $10^{3}$; for $8 \mathrm{keV} \mathrm{X}$-rays, this corresponds to an avalanche size of $\approx 3 \times 10^{5}$ electrons. The charge rate varied from $10 \mathrm{pC} \mathrm{cm}^{-1} \mathrm{~s}^{-1}$ to $0.1 \mu \mathrm{C} \mathrm{cm}^{-1} \mathrm{~s}^{-1}$, depending on the maximum flux tolerated by MSGC plates before the onset of charging-up processes (see Table 2), and on the rate of ageing; as a rule, measurements were suspended when the gain drop exceeded 10-20\% of the original value. Exposures to radiation of detectors lasted from a few hours to several weeks.

Pulse-height spectra recorded on the monitor counter were used to re-normalize the raw data in order to compensate for gain changes due to the ambient temperature, gas composition, and pressure variations; an example of gain fluctuations recorded in the monitor and in a MSGC under test is shown in Fig. 6. Normalization of the MSGC data using the monitor counter provides the corrected data shown in Fig. 6, essentially free from medium-term ambient effects. The normalization factor was phenomenologically adjusted to obtain the best smoothing of the corrected data, and usually has a numerical value around 0.2 (the relative variations in the proportional tube monitor being larger than those of the MSGC).

The reference benchmark for the present measurements was the result of a longterm irradiation of a plate manufactured on low-resistivity glass (MS-1 in Table 2),

\footnotetext{
${ }^{+}$Manufactured by high-pressure water jet cutting by Tecnique Laser SA, Goumoens-la-Ville, Suisse
} 
mounted in the clean box container, and using the custom-made clean gas mixer. In this clean-clean laboratory condition, with the above mentioned set-up we have reached without detectable decrease of gain a total accumulated charge of $130 \mathrm{mC} \mathrm{cm}^{-1}$, see Fig. 7 [5]. In standard operating conditions (an avalanche size of $10^{5}$ electrons) this corresponds to $10 \mathrm{MRad}$ of detected minimum ionizing particles, or 10 years of operation at the highest luminosity of the LHC. Most measurements described in what follows, when realized in less-than optimal conditions, failed to reach such a level of radiation without gain losses, and some scored a lifetime shorter by orders of magnitude. Also, improper manipulation of the gas system or use of non-clean materials appeared to pollute the system affecting all measurements for extended periods of time (see section 4).

\subsection{Standard fibreglass box}

Micro strip plates manufactured on different substrates were mounted in the fibreglass and O-rings assembly shown in Fig. 4. Fig. 8 shows the results of a short-term irradiation of a detector realized by mounting an MS-3 plate in the fibreglass box; a moderate irradiation flux of $200 \mathrm{~mm}^{-2} \mathrm{~s}^{-1}$ at a gain of $2 \times 10^{3}$ was used in order not to exceed the rate capability of the high resistivity substrate; this corresponds to a charge rate of $40 \mathrm{pC} \mathrm{cm}^{-1} \mathrm{~s}^{-1}\left(0.14 \mu \mathrm{C} \mathrm{cm}^{-1} \mathrm{~h}^{-1}\right)$. A very fast drop of gain was observed, reaching $30 \%$ after ten hours of operation $\left(1.4 \mu \mathrm{C} \mathrm{cm}^{-1}\right)$. Suspending the irradiation for several hours (with the anodic voltage on) does not result in recovery, a clear sign of permanent damage. The measurement was repeated several times in different locations on the same plate, with similar results. Fig. 9 shows an interesting fact: if the anodic voltage is switched off for some time after the ageing process is well advanced, at the moment operation is restarted (voltage on) the gain has reset to the original level but drops within minutes to the "aged" value; this is better seen in the enlarged view of Fig. 10 (the zero time is here the moment of application of voltage). In the figure, the time dependence of gain in the aged region and in a "fresh" area are compared. Our interpretation of the results is that in the exposed area a thin polymeric layer grows quickly under irradiation and affects the gain owing to the accumulation of charges on its insulating surface modifying the electric field. Temporary removal of the voltage and/or of the irradiation restores the original field but the surface becomes charged again with a time constant of minutes.

The fact that ageing is a local and permanent effect is demonstrated by the measurement shown in Fig. 11; after the sustained irradiation described above, the gain dependence on position was measured scanning the chamber on a line crossing the exposed region and on a line $5 \mathrm{~mm}$ above: the fresh region was clearly not affected.

Fig. 12 compares the gain measurement realized at two values of flux, in different regions of the chamber not previously irradiated. As could be expected, the detector gain drops faster at higher fluxes, but the ageing rate as a function of collected charge is not independent of the rate: a lower flux tends to produce faster ageing, given the total collected charge. This is a well-known trend, observed in proportional counter, implying that measurements realized at high currents tend to underestimate the ageing rate. Note that in the higher flux measurement, after a certain amount of accumulated charge the detector started showing instabilities and microscopic discharges. This has been a recurrent observation in all our measurements: a substantial gain loss due to ageing is invariably followed by the appearance of discharges and instabilities of operation.

The final evidence that the observed effects are due to the formation of polymers on the surface of the plate comes from the result shown in Fig. 13. A fresh section of the 
chamber was irradiated and aged until reaching a 30\% gain loss; the MSGC plate was then removed from the chamber and cleaned by conventional methods (ultrasonic cleaning with propylic alcohol followed by washing with distilled water). After reassembly, the detector resumed its original gain in the previously exposed and cleaned area, and then followed the same ageing pattern under irradiation.

Note that, at least for low levels of ageing, no modification of the MSGC surface could be detected by direct visual inspection or under a microscope, implying that the surface layer responsible for the gain loss is very thin and/or transparent. Only in the case of irreversible damage due to discharges (the instabilities observed in the gain measurement at high flux in Fig. 12) signs of erosion of the metal could be seen both on the anode and on the cathode strips.

Ageing measurements were repeated using the fibreglass assembly and a MSGC plate manufactured on the higher resistivity electron-conducting glass (MS-2 in Table 2). The result is shown in Fig. 14, compared with the previous measurement made with the ionic glass plate in otherwise identical conditions (clean gas mixer and moderate $\mathrm{X}$-ray flux). The reduced sensitivity to the ageing of detectors manufactured on electronconducting supports was already noticed in previous work [7] but at the time attributed to the different metal used for the detectors (chromium and gold for the ionic and electronic glass respectively).

In the present measurements both MSGC plates were manufactured by the same firm using identical photo-lithographic processing of chromium. It is not known, at the present time, if the smaller ageing rate is an outcome of a decreased polymerization yield or if it is simply a manifestation of a reduced sensitivity to local charge accumulation on the low-resistivity glass devices.

\subsection{Clean box assembly}

In order to cross-check our previous measurement of stable long-term operation in very clean conditions obtained a year ago (see Fig. 7) we have mounted an MS-3 plate in the clean box assembly. Figure 15 shows a medium-term gain measurement realized in these conditions (clean box, clean gas mixer); the previous results, obtained with an identical MS-3 plate in the fibreglass box is also shown for comparison. Although, because of the limited rate that can be used with the ionic glass plate we could not reach very large charge doses, the difference in behaviour is evident: it confirms that fast ageing is indeed a consequence of the use of unsuitable materials in the chamber assembly.

\subsection{Glass box assembly}

The last set of measurements was realized in glass-box chambers schematically shown in Fig. 5. These detectors provided results very close to those obtained in the clean box, and are obviously much better suited for building devices to be used in experimental set-ups. After assembly, the chambers were heated for several hours at $80{ }^{\circ} \mathrm{C}$ in vacuum to outgas the materials used for manufacturing; high voltage was applied only several days after mounting the detectors in the gas line. Results obtained with an MS-2 plate (electron conducting glass with $10^{12} \mathrm{ohm} \mathrm{cm}$ ) are shown in Fig. 16; a small gain loss is observed (about $10 \%$ after $12 \mathrm{mC} \mathrm{cm}^{-1}$ ), that we think was due to small residual outgassing from the epoxy used for assembly. The ageing rate is however orders of 
magnitude smaller than for the same plate mounted in the fibreglass box, and suggests that a solution to the problem in practical detectors is at reach.

\section{CONCLUSIONS}

In a systematic set of measurements we have verified the extreme sensitivity of MSGCs to ageing effects due to gas polymerization in the avalanches induced by radiation. A negligible ageing rate was demonstrated in laboratory conditions (MSGC plates mounted in a clean all-metal and ceramics box) that can hardly be used in a experimental set-up; a more practical chamber assembly, making use of thin glass frames pasted between the MSGC plate and the drift electrode using vacuum-grade epoxy, has provided very promising results but requires further investigation.

For high-rate applications, such as those envisaged for LHC detectors, the greatest care has to be taken in the choice of the operating gas and of the materials used in manufacturing the detectors in order to guarantee long-term correct operation, as well as of the conception and the manipulations on the gas system. As additional evidence of this statement we reproduce in Fig. 17 the results of a measurement realized with a new MSGC plate in supposedly "clean" conditions, after a long set of other measurements in which suspect materials were used: despite several days of flushing clean gas through the experiment, the system remained polluted and substantial ageing was observed, when resuming the irradiation, in conditions in principle identical to those illustrated by the measurement in Fig. 7.

The "glass chamber" construction seems very promising in view of the extended use of MSGC detectors in LHC set-ups. The assembly is simple and cheap, and adds the minimum amount of materials. In collaboration with the RD-10 project at CERN we are testing outgassing properties of various materials and epoxies that may be considered as alternatives to those described in this paper (see Table 3). In particular, the use of several high grade polymers such as VECTRA ${ }^{+}$and RYTON* is very attractive; they are known for their extremely low residual pollutants level (they have been considered for use in warm liquid calorimeters); they have the advantage of being lighter and less fragile than glass, and can be injection-moulded directly into the desired shape including gas inlets and distribution. The picture in Fig. 18 shows some examples of frames realized by highpressure water jet cutting of glass and VECTRA plates; the larger size $\left(244 \times 116 \mathrm{~mm}^{2}\right)$ corresponds to the requirements of the Compact Muon Solenoid (CMS) detector for LHC. Fig. 19 shows a prototype medium size MSGC, having an active area of 80x80 $\mathrm{mm}^{2}$, realized by the technique described. All electrical connections for signals and HV are realized externally after manufacturing of the chamber, thus ensuring minimum manipulation of the active part of the plate before encapsulation in the covered frame.

\footnotetext{
+ VECTRA C150: Tradename of Hoechst AS, Frankfurt am Main, Germany and Celanese, USA.

* RYTON R4: Tradename of Philips, Eindhoven, The Netherlands.
} 


\section{REFERENCES}

[1] A. Oed, Nucl. Instrum. Methods A263 (1988) 351.

[2] F. Angelini, R. Bellazzini, A. Brez, E. Forcardi, T. Lomtadze, M.M. Massai, G. Spandre, M. R. Torquati, R. Bouclier, J. Gaudaen, F. Sauli and A. Perret, CERN 90-10 Vol.3 p. 222 (Proc.LHC Workshop, Aachen 4-9 October 1990).

[3] F. Angelini, R. Bellazzini, A. Brez, M.M. Massai, G. Spandre, M. Torquati, R. Bouclier, J. Gaudaen and F. Sauli, Nucl. Phys. 23A (1991) 254.

[4] M. Geijsberts, F.G. Hartjes, J.G. Pannekoek, J. Schmitz and F. Udo, Nucl. Instrum. Methods A313 (1992) 377.

[5] R. Bouclier, G. Million, Yu.N. Pestov, L. Ropelewski, F. Sauli and L.I. Shekhtman, Nucl. Instrum. Methods A332 (1993) 100.

[6] RD-28 Status Report, CERN/DRDC/93-34 (13 August, 1993).

[7] R. Bouclier, J.J. Florent, J. Gaudaen, G. Million, A. Pasta, L. Ropelewski, F. Sauli and L.I. Shekhtman, Nucl. Instrum. Methods A323 (1992) 240.

[8] J.E. Bateman and J.F. Connolly, Substrate-induced instability in gas microstrip detectors, RAL-92-085 (December 1992).

[9] S. Brons, W. Brückner, M. Heidrich, I. Konorov and S. Paul, Use of ultra thin semi-conductive layers as passivation in MSGCs, CERN/PPE 93-194 (25 October 1993).

[10] M. Salomon, J. Armitage, M. Dixit, W. Faszer, D. Lam and G. Oakham, Some properties of gas microstrip detectors made on tedlar substrates and operating with $\mathrm{CF}_{4}$-Isobutane gas, subm. IEEE 1993 Nucl. Sci. Symp., San Francisco (2-5 November 1993).

[11] R. Bouclier Ch. Garabatos, G. Manzin, F. Sauli, L.I. Shekhtman, T. Temmel, G. Della Mea, G. Maggioni, V. Rigato and I. Logachenko, Development of MSGC on substrata with electronic conductivity, CERN-PPE/93-192 (29 October 1993), subm. IEEE 1993 Nuclear Science Symposium, San Francisco (2-5 November 1993).

[12] Yu.N. Pestov and L. I. Shekhtman, Nucl. Instrum. Methods A338 (1994) 368.

[13] L.Alunni, R.Bouclier, G.Fara, Ch.Garabatos, G.Manzin, G.Million, L. Ropelewski, F.Sauli, L.I.Shekhtman, E.Daubie, O.Pingot, Yu.N. Pestov, L.Busso and S.Costa, Performance of MSGC manufactured on electronic and ionic conductivity substrata in various operational conditions, CERN-PPE/93-179 (6 October 1993). Presented at the $3^{\mathrm{d}}$ London Conference on Position Sensitive Detectors, Brunel Univ. (6-10 September 1993).

[14] J.A. Kadyk, Nucl. Instrum. Methods A300 (1991) 436.

[15] R. Bouclier, Ch. Garabatos, A. Peisert-Elliott, L.I. Shekhtman, T. Temmel, J.C. Santiard and F. Sauli, Signal analysis in micro-strip gas chambers (in preparation)at

[16] RD-10: A study to improve the radiation hardness of gaseous detectors for use at very high luminosity, CERN/DRDC/90-40 (8 November 1990) and CERN/DRDC/93-52 (22 December 1993).

[17] R. Bouclier, M. Capeans, C.Garabatos, R.D. Heuer, M. Jeanrenaud, T.C. Meyer, F. Sauli and K. Silander, Result of wire chamber ageing tests with $\mathrm{CH}_{4}$ and DME based gas mixtures, CERN-PPE/94-40 (9 February 1993), to be published in Nucl. Instrum. Methods.

[18] R. Bouclier, M. Capeans, C.Garabatos, G. Million, F. Sauli and K. Silander, Outgassing of materials used in micro-strip chambers manufacturing (in preparation). 


\section{FIGURE CAPTIONS}

Fig. 1: Experimental set-up for the long-term ageing measurements. An X-ray beam is used to irradiate the MSGC detector; the attenuated beam is detected in a single-wire proportional counter for monitoring.

Fig. 2: The custom-made clean gas mixer. An Ar-DME 90-10 mixture was used in the measurements described here.

Fig. 3: The clean box assembly for testing MSGC plates in clean conditions. Only ceramics, glass and metals are used.

Fig. 4: The fibreglass box, made with conventional frames assembled with bolts and synthetic rubber joints.

Fig. 5: The glass box: a thin glass frame with gas inlet and outlet is pasted on the MSGC plate and on the drift electrode, realized with a thin glass plate. Vacuum grade epoxy is used for the assembly.

Fig. 6: The normalization procedure used to reduce daily variations of gain. The average pulse height recorded with the proportional tube monitor is unfolded with the raw data of the MSGC detector to obtain the normalized curve.

Fig. 7: Reference measurement of gain as a function of collected charge in the best operating conditions (a low resistivity MSGC plate in the clean box).

Fig. 8: Fast ageing of a MSGC (MS-3) mounted in the fibreglass box as a function of irradiation time. After $10 \mathrm{~h}$ of irradiation, the $\mathrm{X}$-ray beam was removed but the voltage on the chamber left on: at resuming the exposure, the ageing process continues from the same gain value.

Fig. 9: Ageing measurement on MS-3 in the fibreglass box, with the HV on the chamber switched off for several hours during the irradiation. At application of voltage, the gain drops within minutes to the previous, degraded value. The region of time after re-application of voltage is shown better in the next figure.

Fig. 10: Enlarged view of the gain behaviour in the irradiated region of the chamber at application of voltage after a period with the HV off (curve A). For comparison, the time behaviour of gain in a non-irradiated (fresh) region of the same chamber is also shown (curve B).

Fig. 11: The gain drop due to ageing is a local effect, as demonstrated measuring the gain as a function of position on a line crossing the irradiated area and a line just above it. Fig. 12: Dose-rate dependence of ageing. Irradiation at higher flux tends to underestimate the ageing effects. Note also the instabilities of operation accompanied by irreversible damage (due to discharges) that occurs if one exceeds a certain amount of ageing.

Fig. 13: Careful cleaning of the MSGC after irradiation restores the original gain, evidence that ageing is caused by polymeric deposits on the surface of the plate.

Fig. 14: Dependence of ageing rate on the nature of the substrate used for manufacturing the MSGC: an e.c. glass (MS-2) and an ionic glass (MS-3). The measurements have been realized in identical conditions (fibreglass box assembly).

Fig. 15: Gain dependence on charge measured for the same MSGC plate (MS-3) mounted in the clean box and in the fibreglass box assemblies.

Fig. 16: Long-term gain dependence on charge measured for the MS-2 plate mounted in the glass box (Fig. 5). Some gain loss is observed, probably due to residual outgassing of the epoxy used for manufacturing the detector. The total accumulated charge,corresponds to one year of operation at the highest LHC luminosity (about $12 \mathrm{mC} \mathrm{cm}^{-1)}$.

Fig. 17: Ageing measurement recorded in supposedly "clean" conditions, but after a long succession of other measurements involving manipulation of the gas system and use of less than clean detectors. A previous measurement is shown for comparison.

Fig. 18: Examples of thin $(0.5 \mathrm{~mm}$ thick) frames realized in various materials (glass, VECTRA, RYTON) for the assembly of chambers as described in the text. The largest frame is $244 \times 116 \mathrm{~mm}^{2}$.

Fig. 19: Prototype medium-size MSGC realized with a glass frame and a glass top. The active area is $80 \times 80 \mathrm{~mm}^{2}$. 


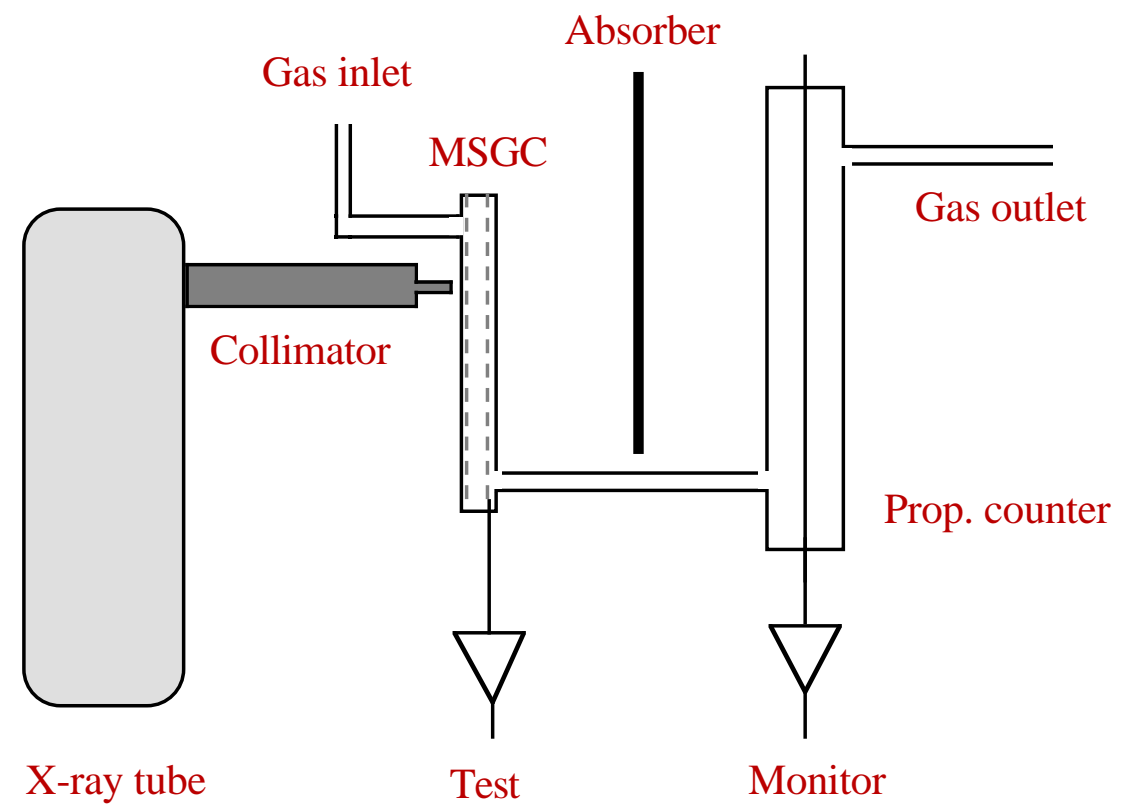

Fig. 1

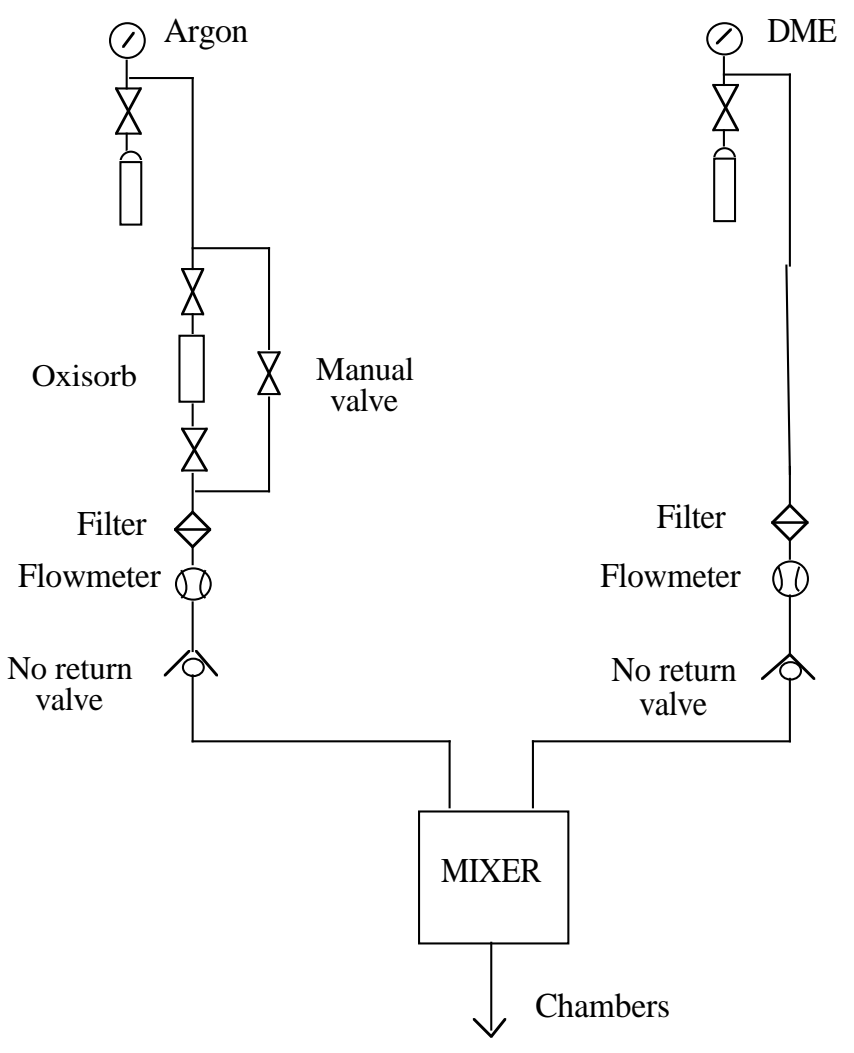

Fig. 2 


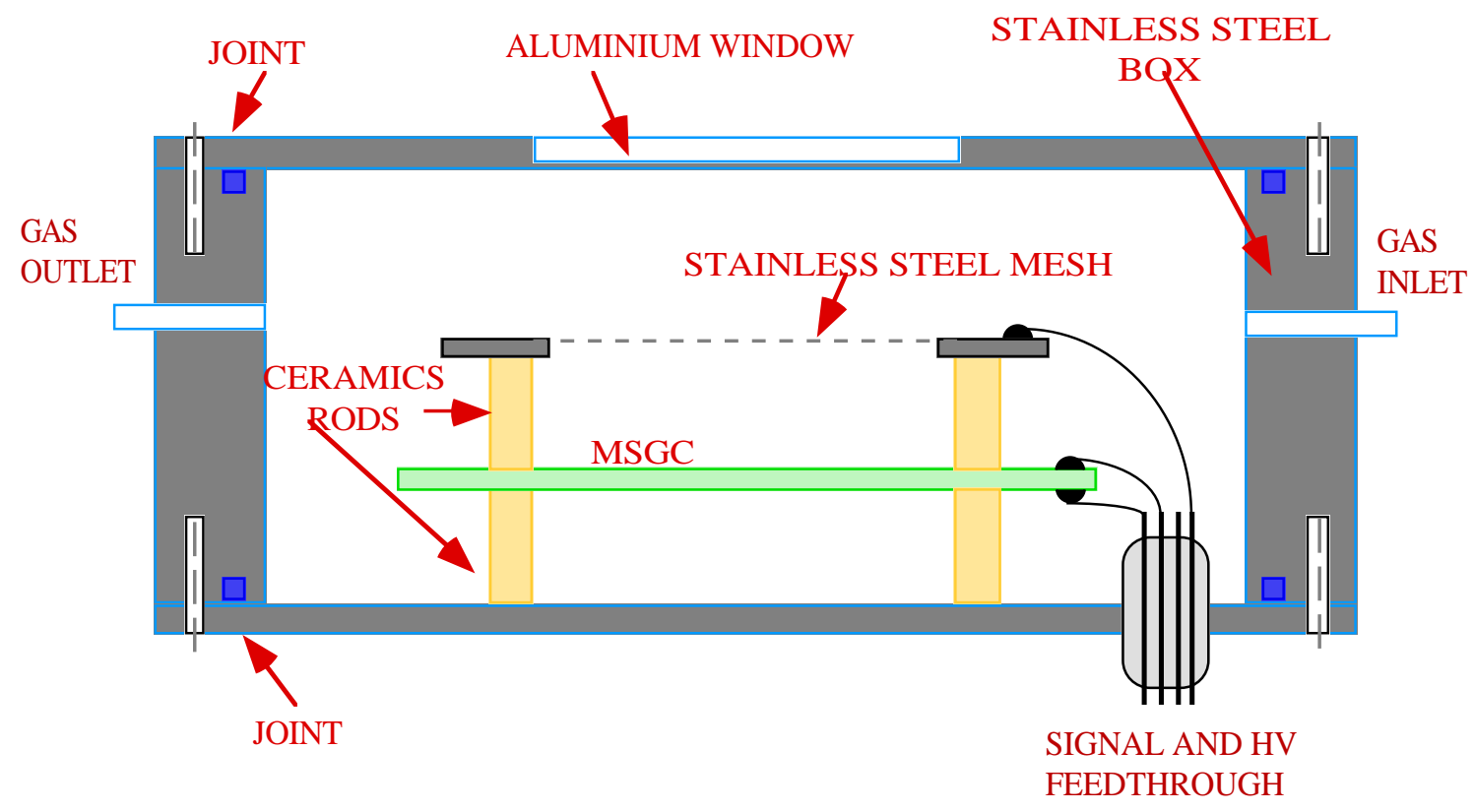

Fig. 3

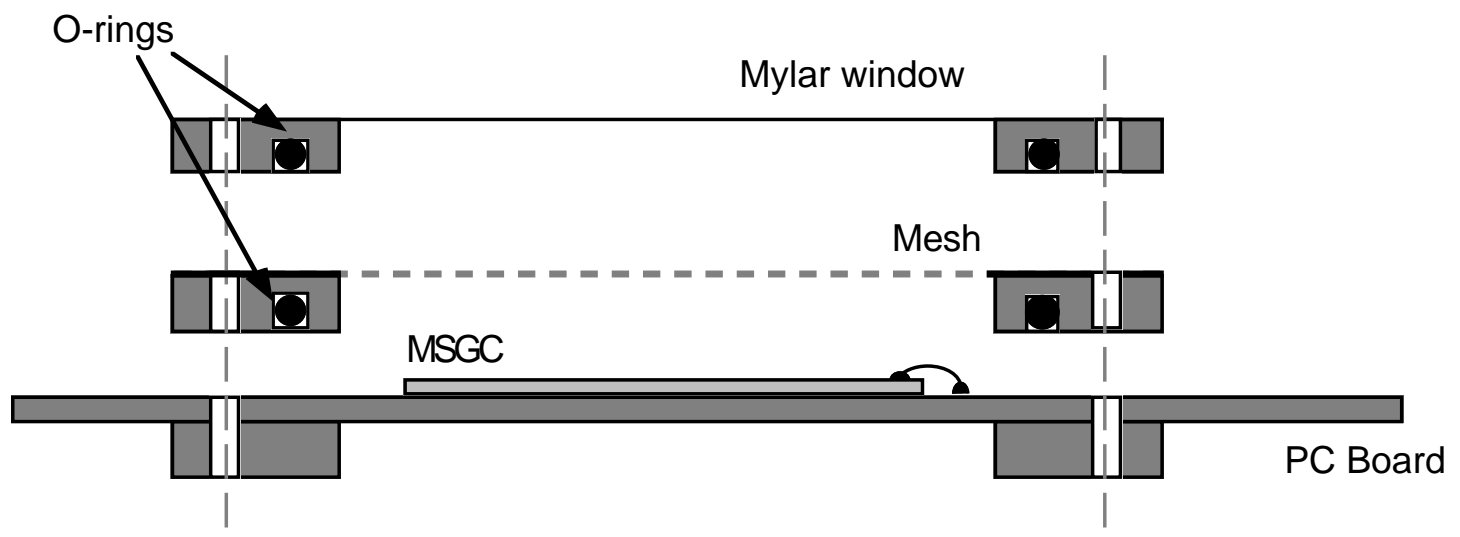

Fig. 4

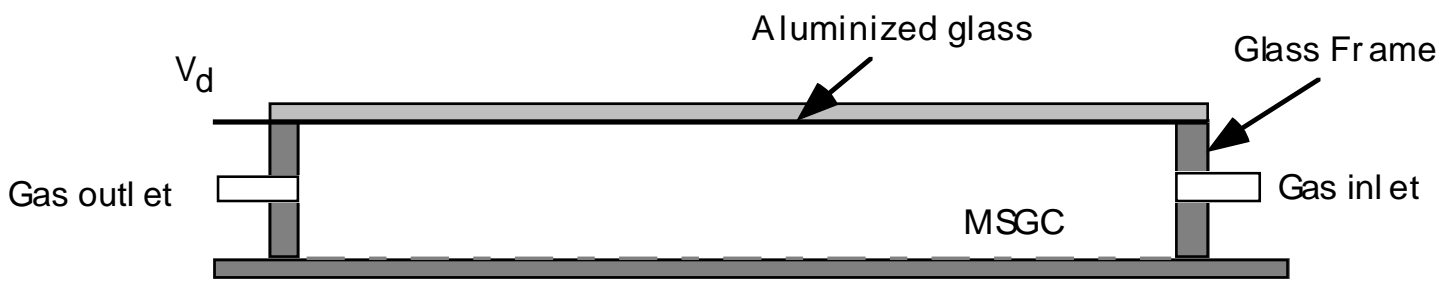

Fig. 5 


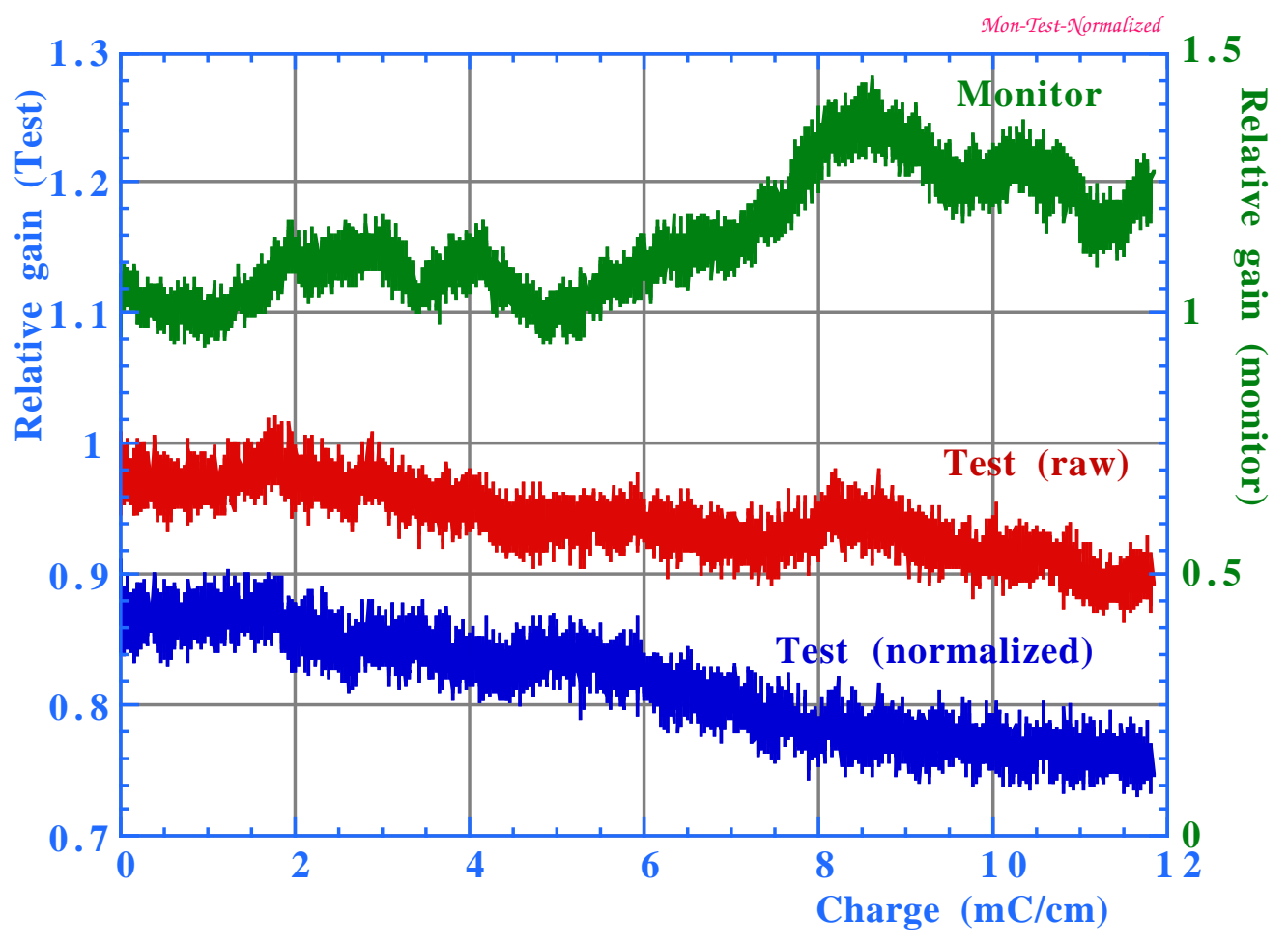

Fig. 6

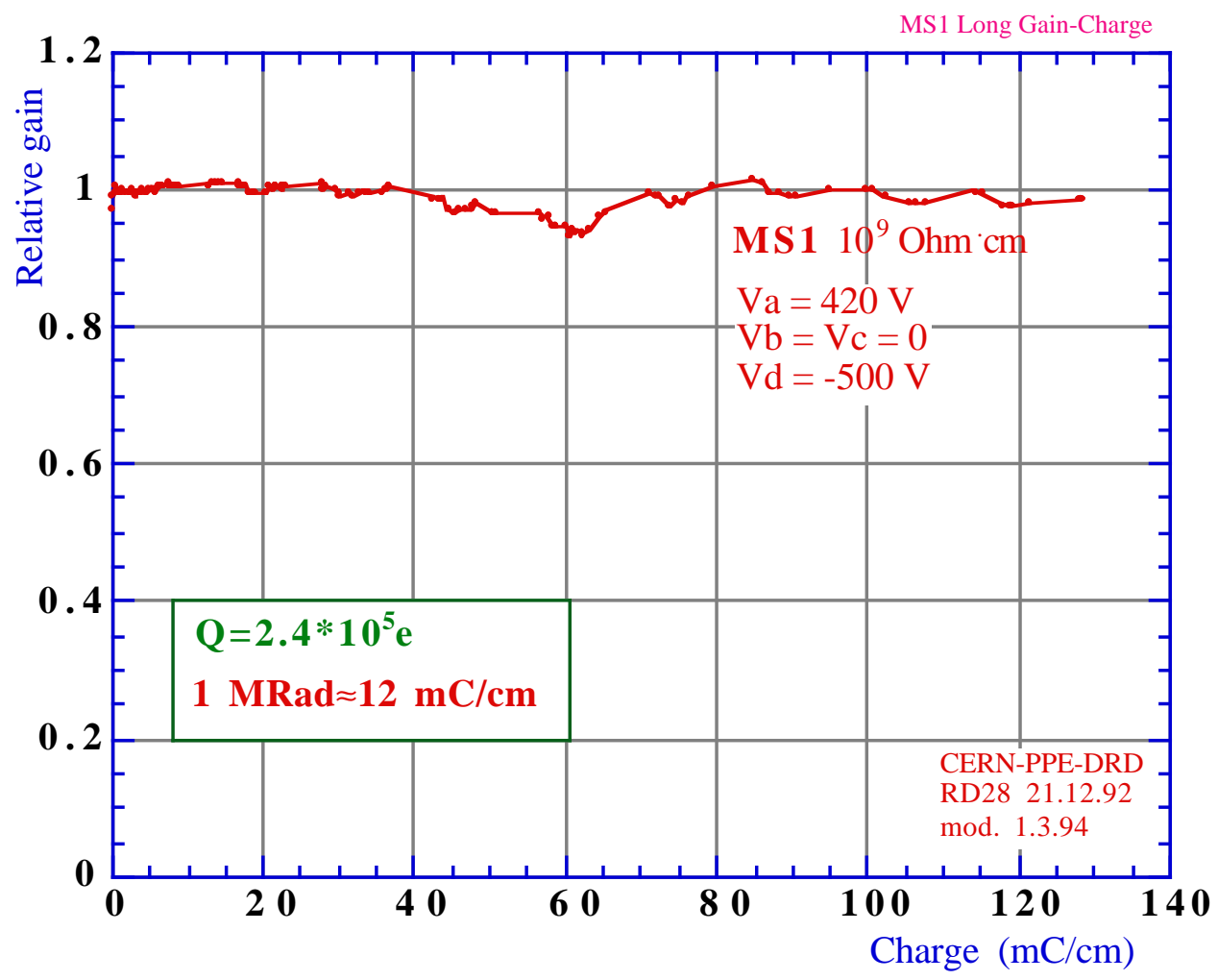

Fig. 7 


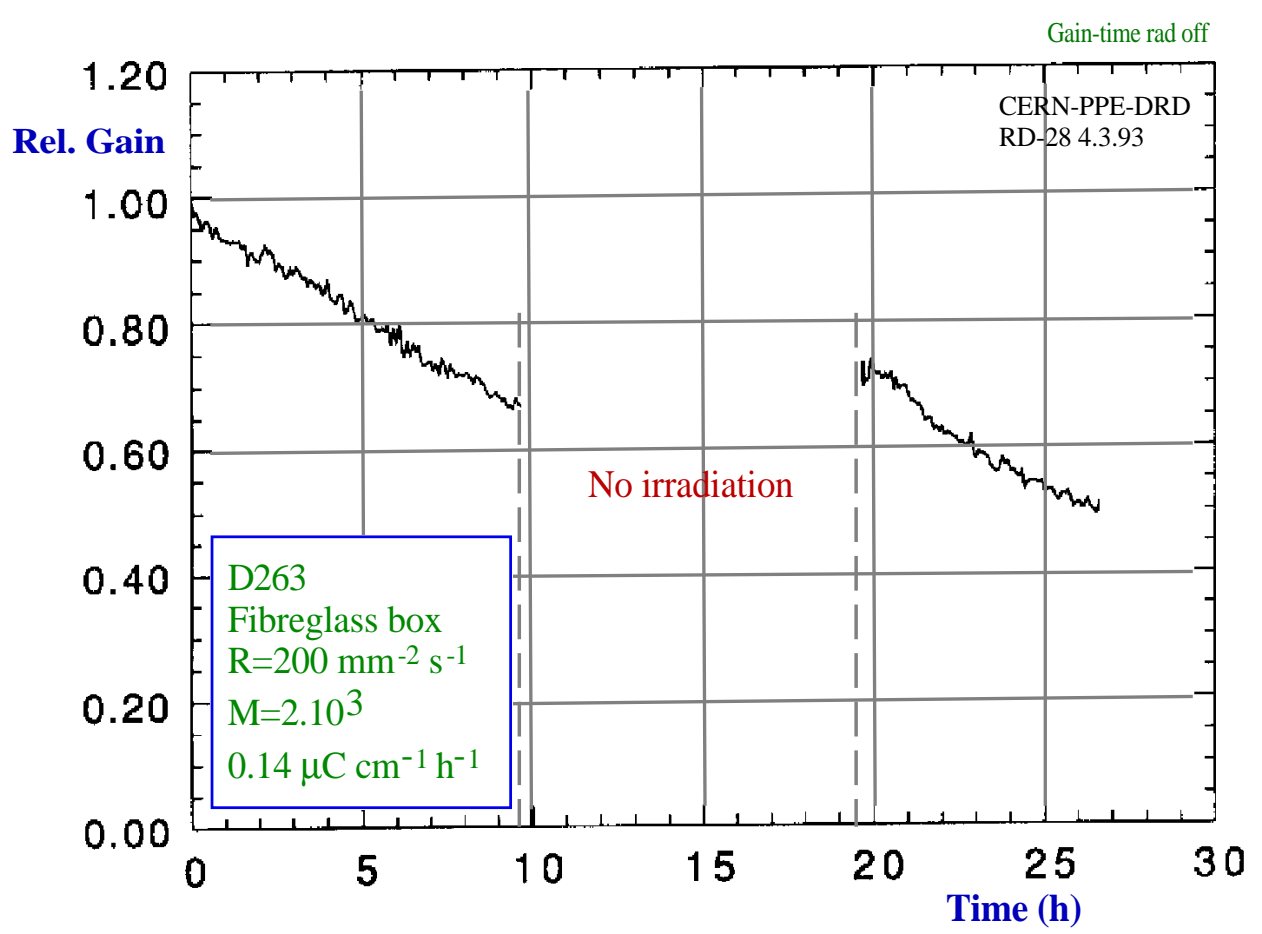

Fig. 8

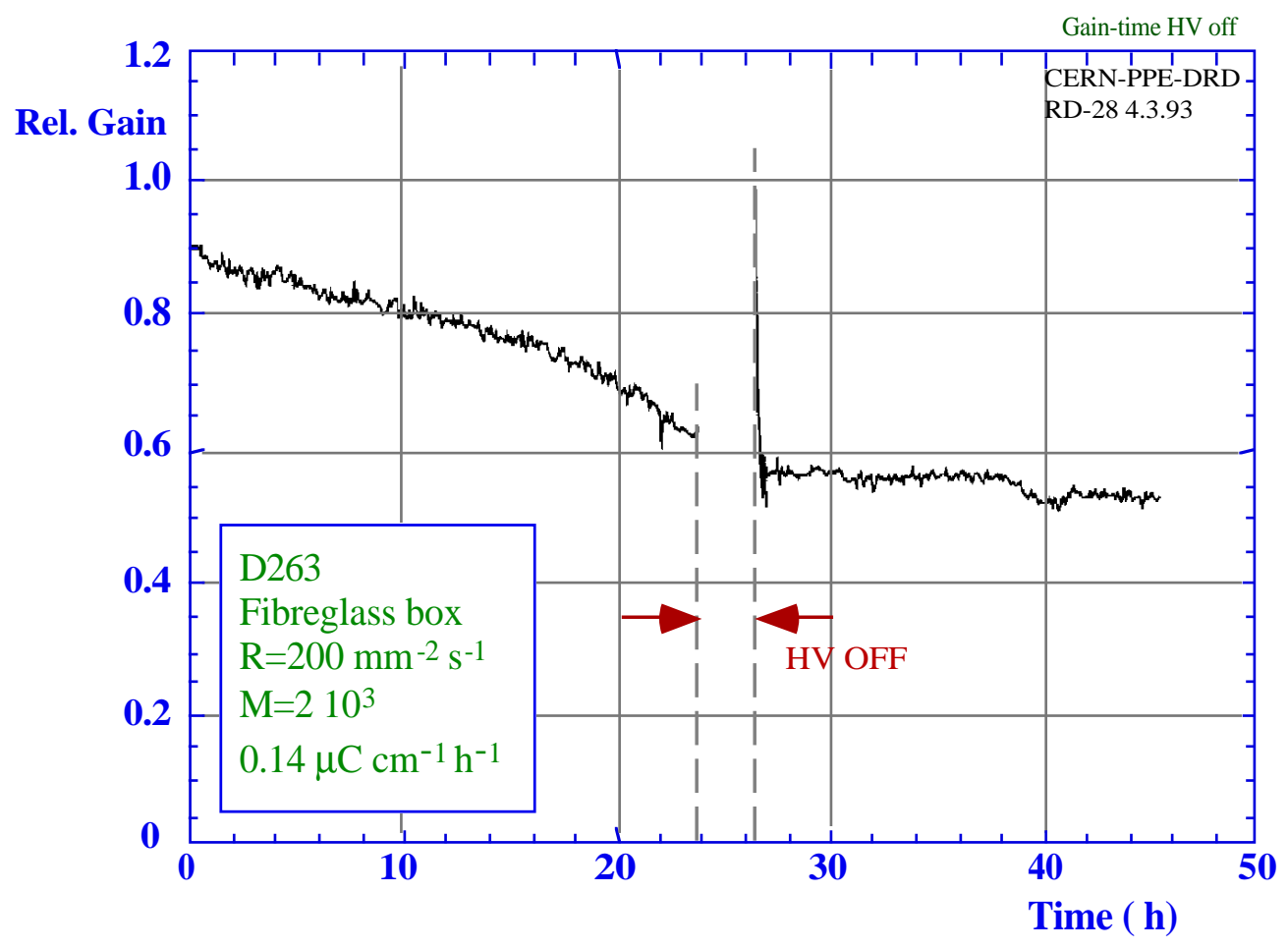

Fig. 9 


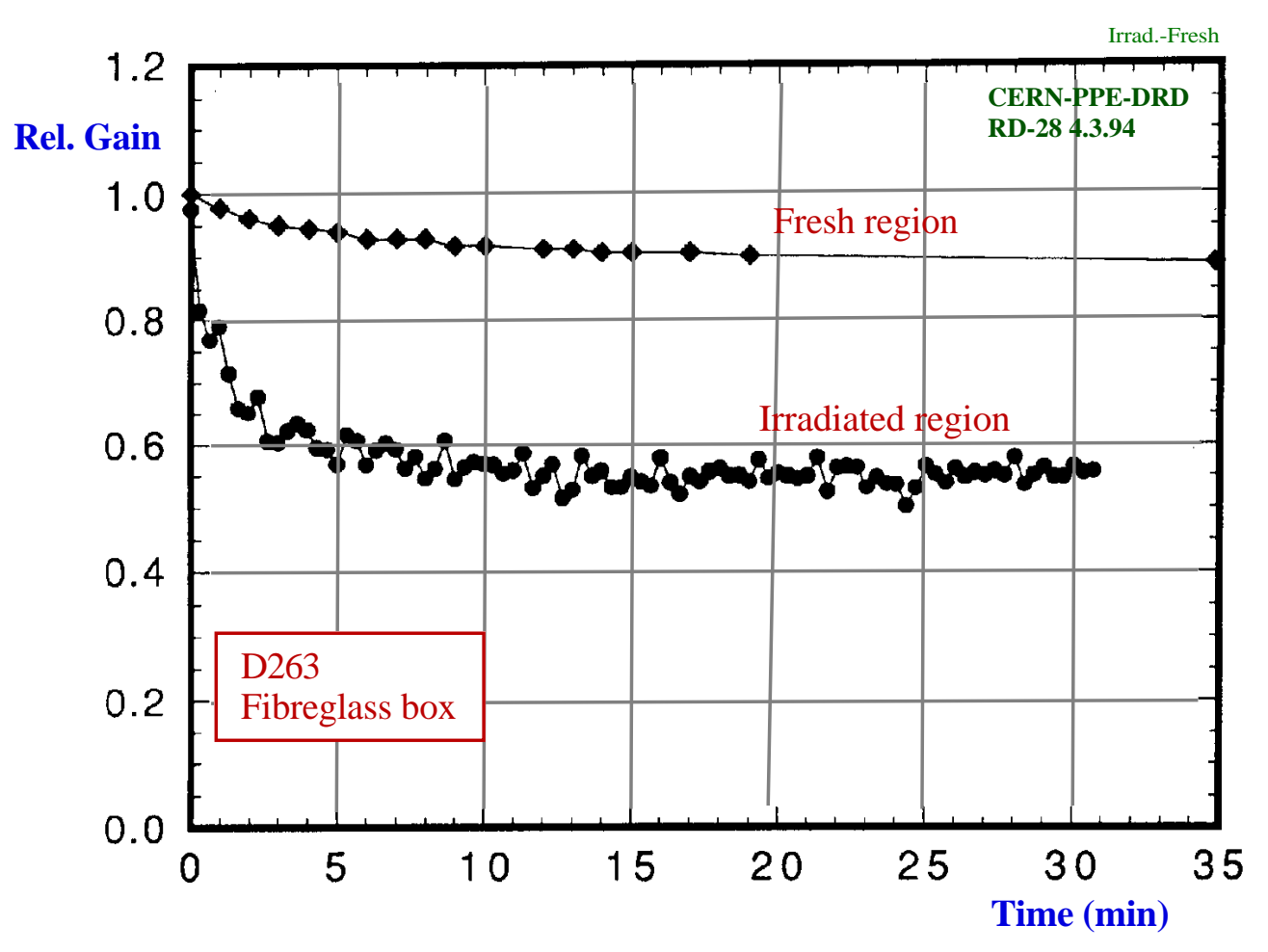

Fig. 10

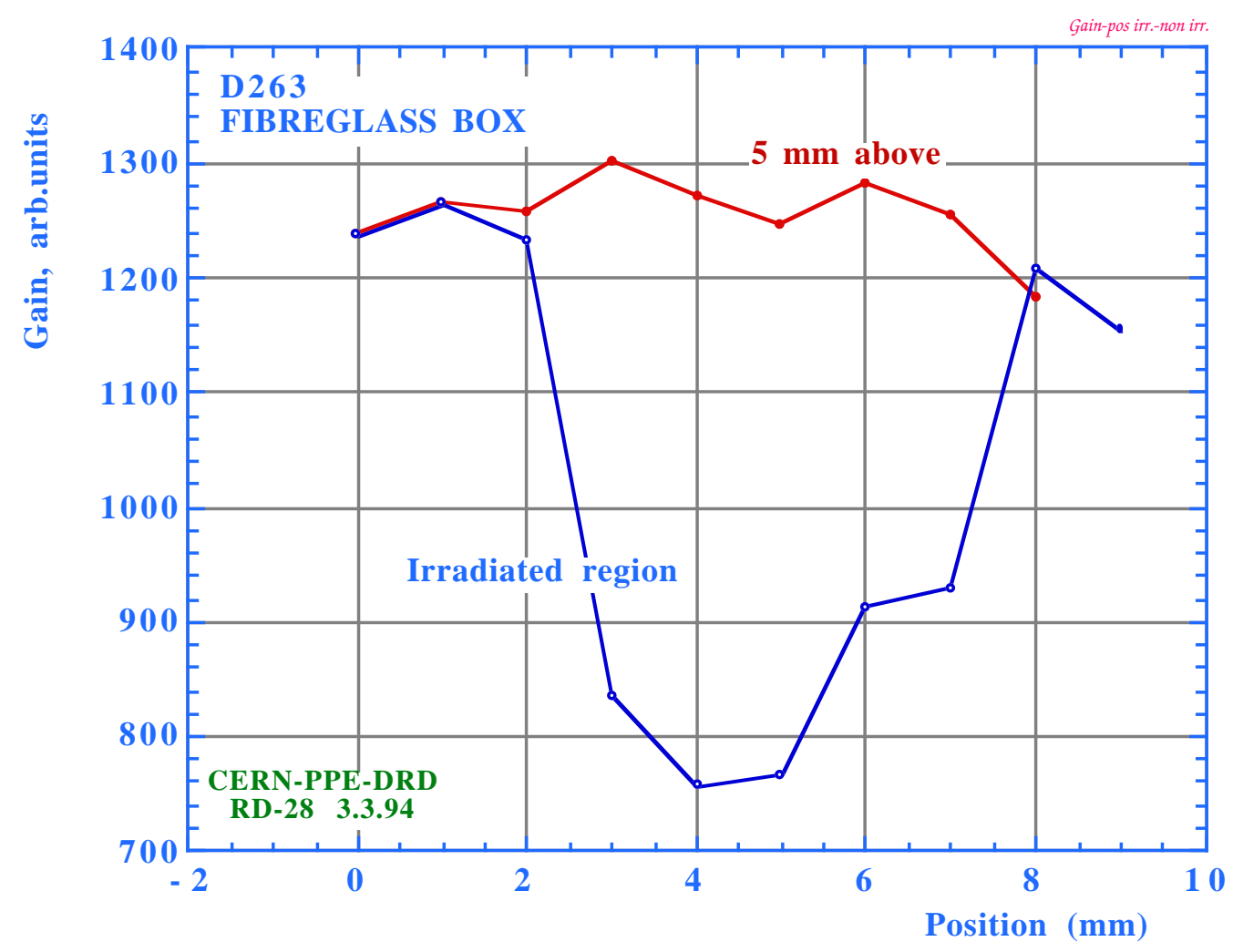

Fig. 11 


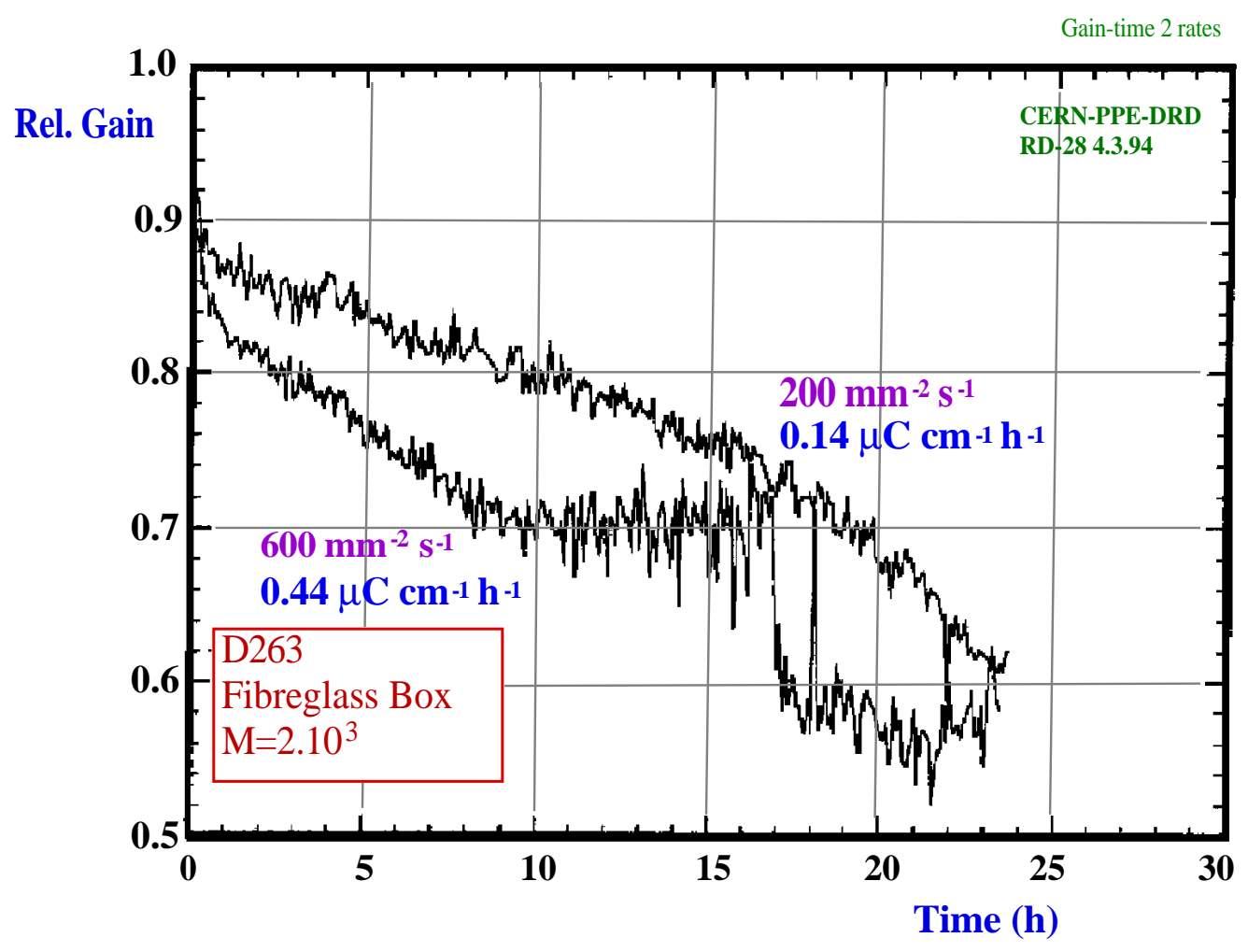

Fig. 12

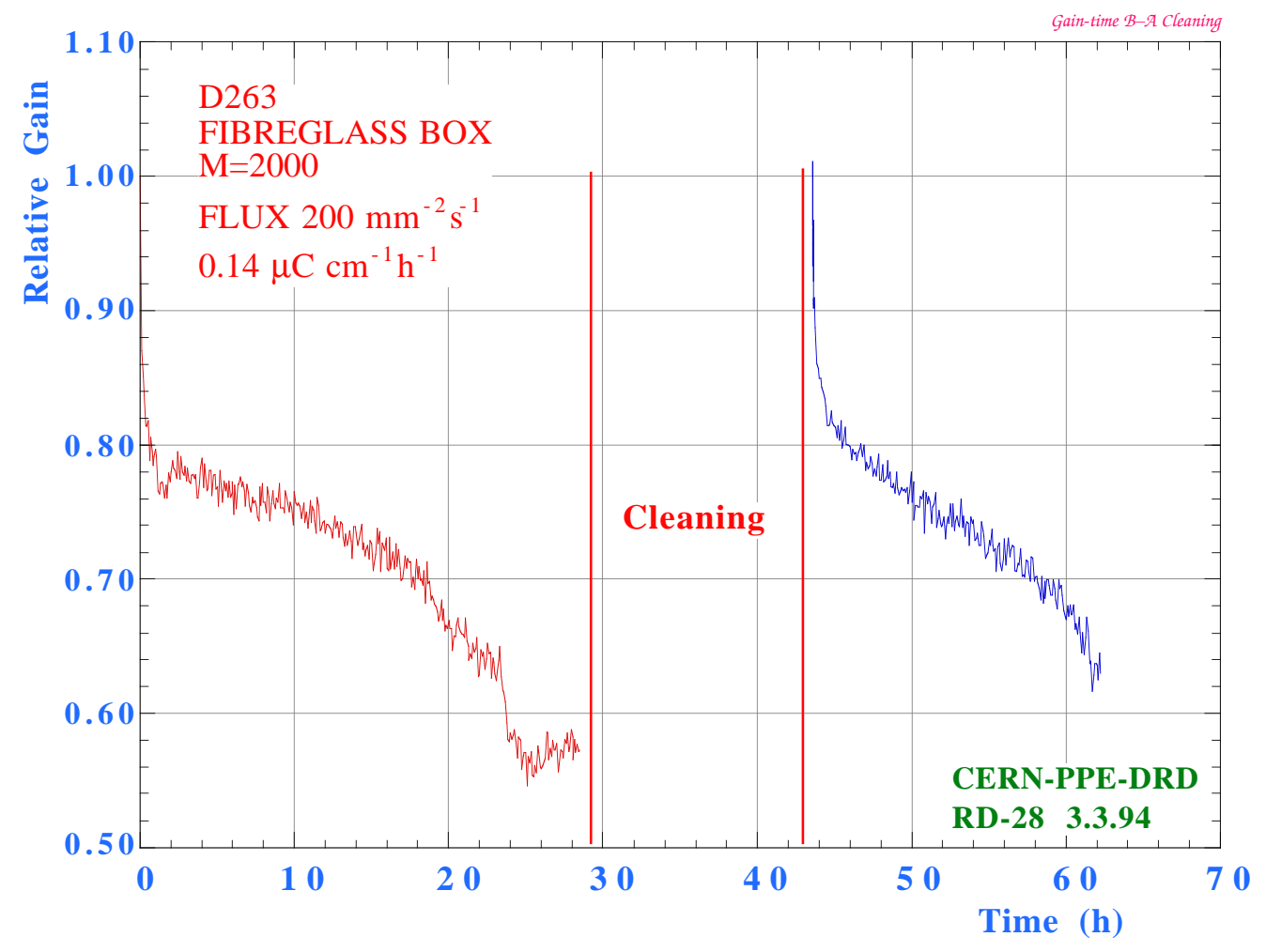

Fig. 13 


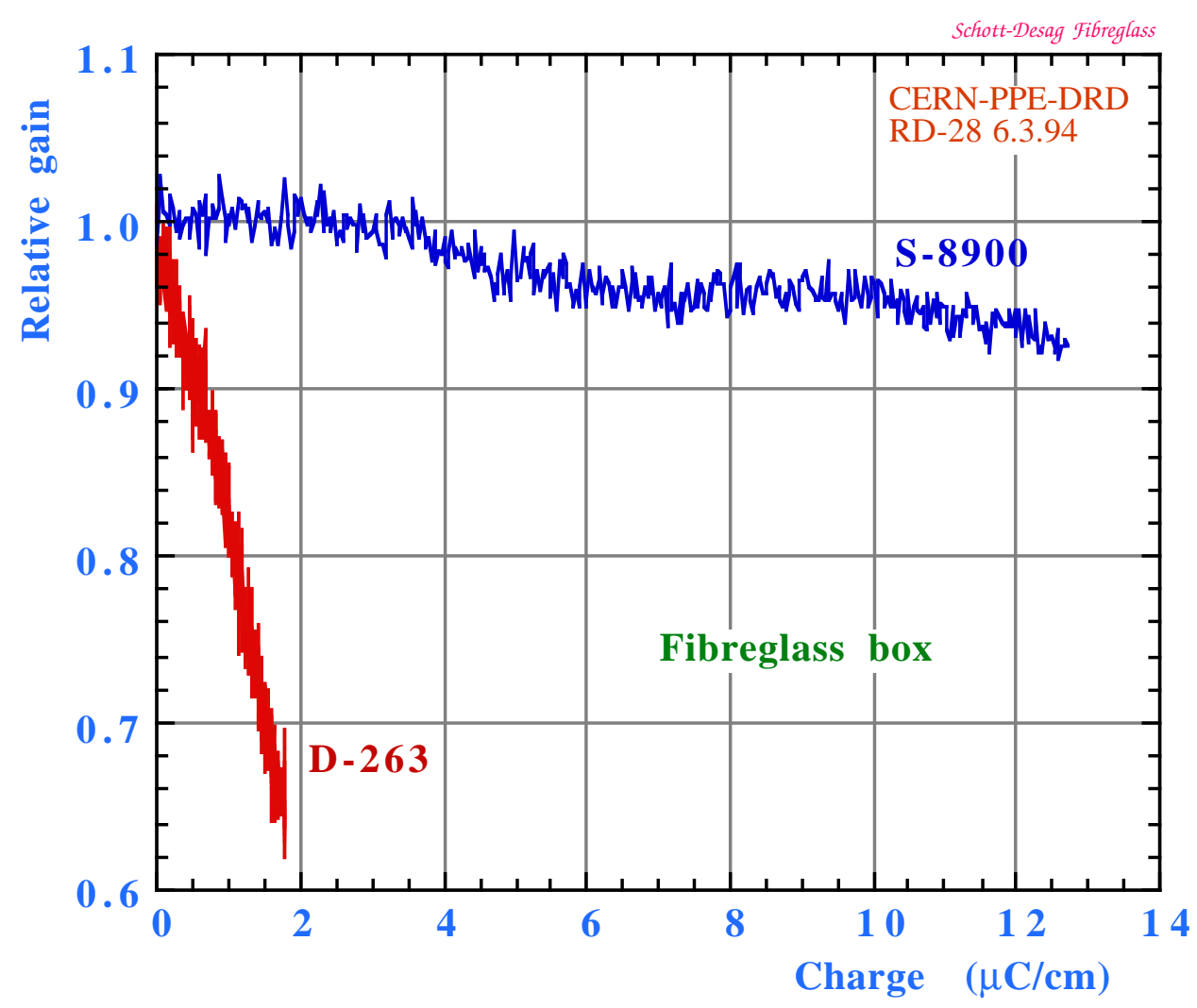

Fig. 14

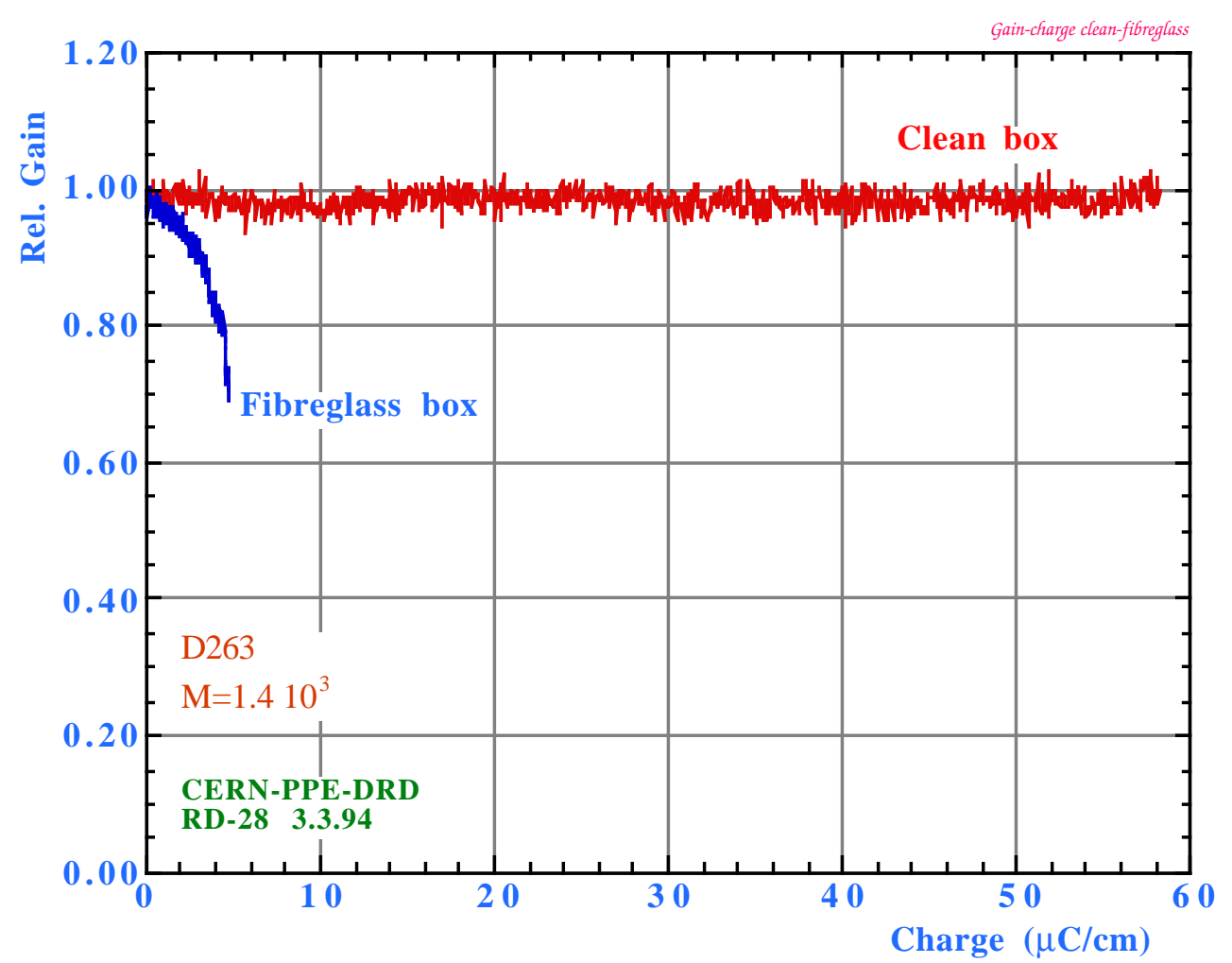

Fig. 15 


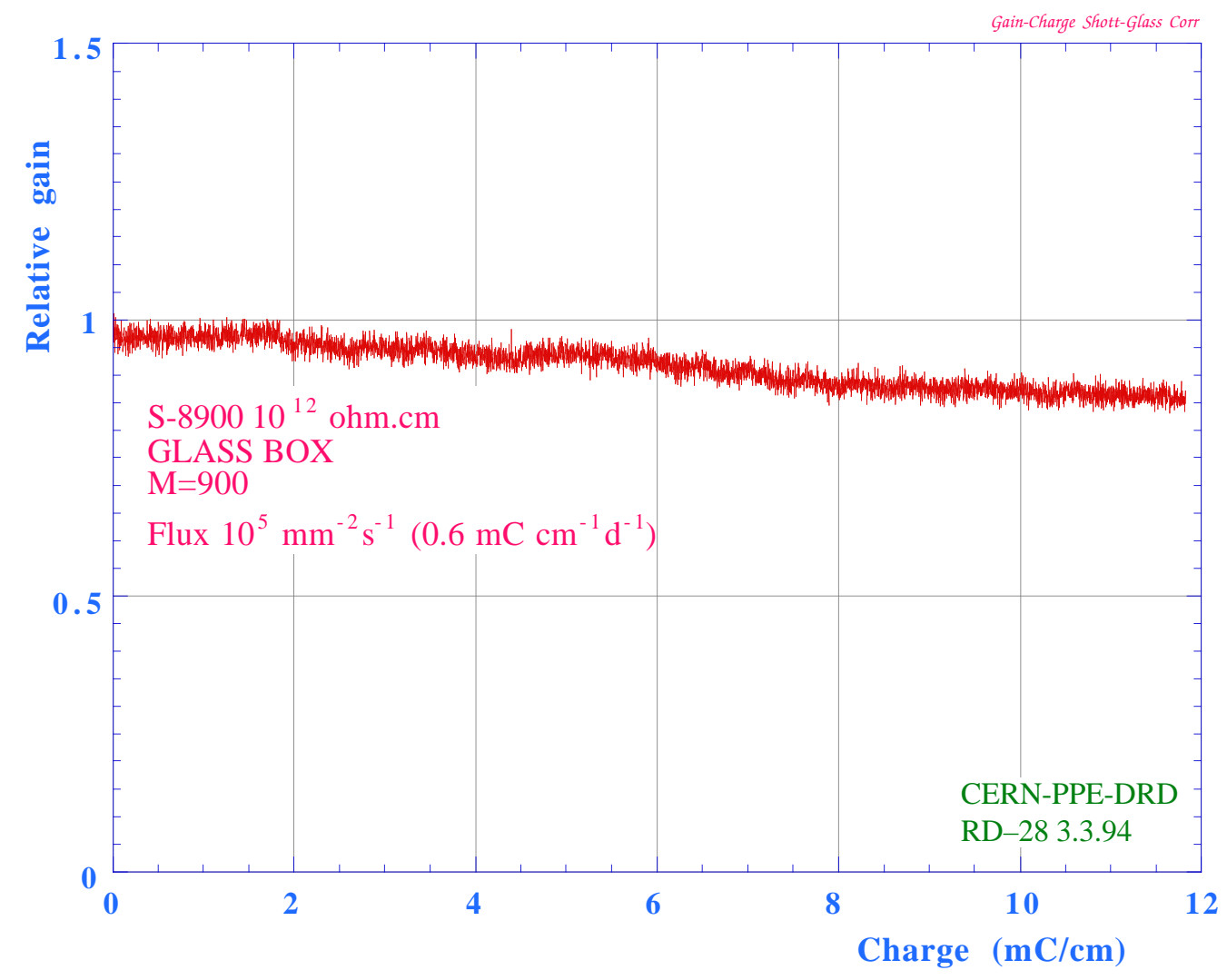

Fig. 16

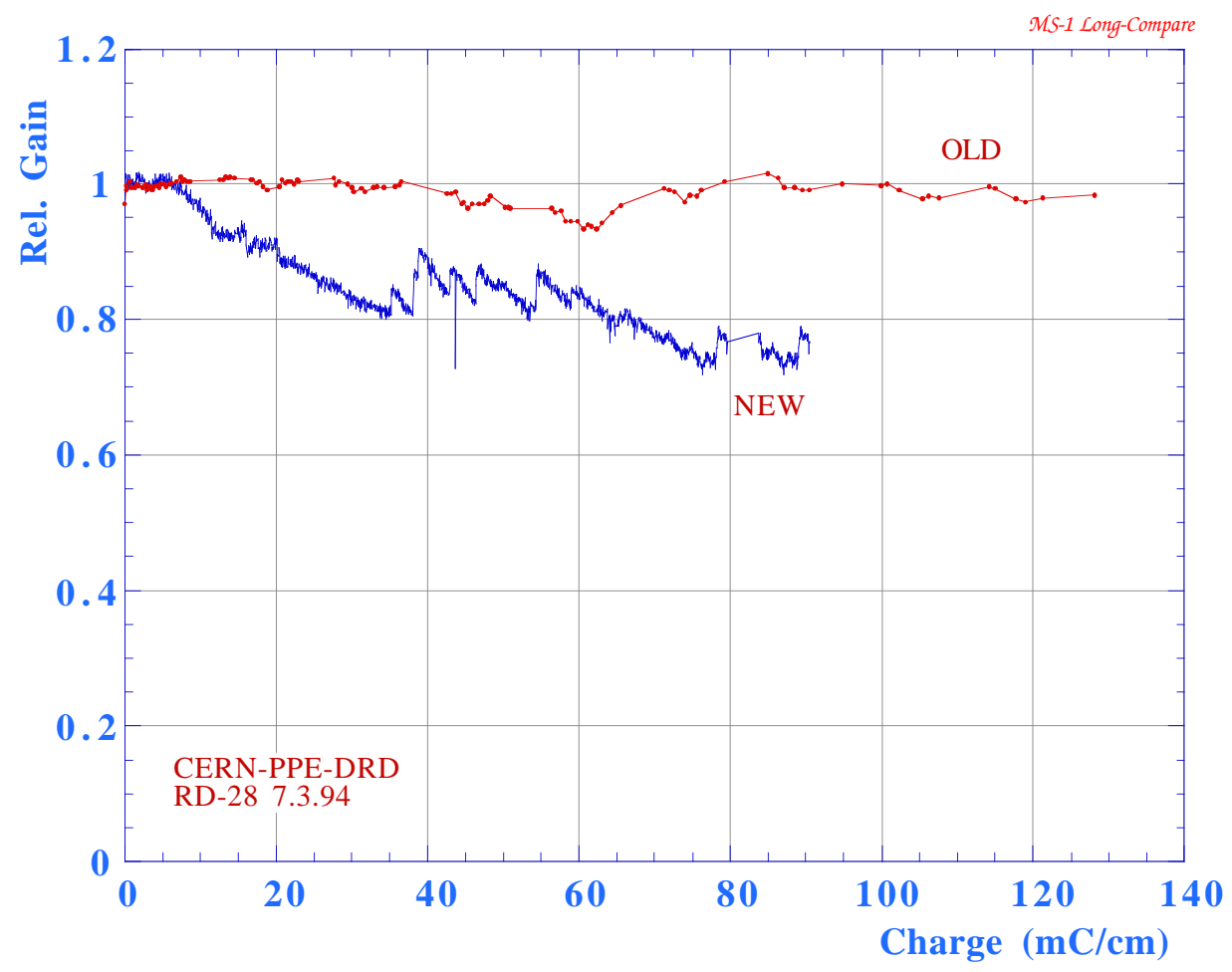

Fig. 17 
Fig. 18

Fig. 19 